\title{
Chip formation in machining hybrid components of SAE1020 and SAE5140
}

\author{
B. Denkena ${ }^{1} \cdot$ B. Breidenstein ${ }^{1} \cdot$ A. Krödel ${ }^{1} \cdot$ V. Prasanthan ${ }^{1}$ (i)
}

Received: 31 July 2020 / Accepted: 26 October 2020 / Published online: 13 November 2020

(c) The Author(s) 2020

\begin{abstract}
The requirements for massive high-performance components are constantly increasing. In addition to the reduction of component weight, requirements such as smaller design, more functionality and longer lifetime are increasing. By joining different materials in one component, these contradictory requirements can be met. In the process chain of manufacturing hybrid components, machining as the final step has a decisive influence on the application behavior and service life due to the surface and subsurface properties generated. Thereby thermomechanical loads during machining determine the final subsurface properties and the chip formation mechanisms determine the final surface properties of components. However, for the specific adjustment of required surface and subsurface properties, first of all an understanding of the generation of the addressed properties in the material transition zone is necessary. In the current work, the chip formation and the mechanical loads in the transition zone of hybrid components are presented. Within the scope of orthogonal cutting investigations, the influence of process parameters and tool microgeometry on mechanical loads and chip formation is analyzed. Chip forming has a significant influence on the surface properties of the hybrid component. The chip formation depends on the hardness of the machined material. During machining of hybrid components an abrupt change of the chip shape takes place in the material transition zone. The process variables influence the level in the surface topography of hybrid components.
\end{abstract}

Keywords Orthogonal cutting $\cdot$ Chip formation · Hybrid components $\cdot$ Surface topography

\section{Introduction}

Today's production increasingly demands environmentally friendly and resource-saving manufacturing of products. This demand extends from the automotive industry to medical technology, energy technology and general mechanical engineering [1-4]. In the automotive industry, for example, the aim is to reduce $\mathrm{CO}_{2}$ emissions by reducing vehicle weight [5].

Reducing weight while at the same time increasing resistance to induced load stresses leads to partially contradictory material properties. The requirements can therefore not be met by simply substituting one material with another. However, by combining different materials in one component, it is possible to achieve different requirements such as a reduction in weight

V. Prasanthan

prasanthan@ifw.uni-hannover.de

1 Institute of Production Engineering and Machine Tools, Leibniz University Hannover, An der Universität 2, 30823 Garbsen, Germany and a simultaneous increase in mechanical strength. The combining of two or more different materials in one component is defined as hybrid construction. Hybrid components have macroscopically different material properties. They are primarily manufactured by forming or molding and build a structural and functional unit. Hybrid components can be divided into subareas of monolithic materials and material compound. All subareas combined build one united system, a hybrid component. Hereby no additional material is used to combine the different materials during the joining process. Instead of a material joint, an intermetallic phase or joining zone is created. The hybrid construction allows the design of components with different materials that are locally adapted to the respective requirements. This is the focus of the Collaborative Research Centre (CRC) 1153, in which the new process chain "Tailored Forming" is investigated [6]. In this new process chain, the blanks are not joined at the end, as in the current state of the art, but at the beginning of the process chain. Due to the simple blank geometry (shafts), a secure material bond is created during the joining process. Friction welding, deposition welding and extrusion are used and examined as joining methods. The 
subsequent forming processes even improve the properties of the bonding zone [7-9].

Machining as the final step in the process chain of hybrid component production determines the final surface and subsurface properties [10-13]. Therefore it is necessary to reach an adequate level of accuracy of shape and dimension for the workpiece. Hybrid components require, more than homogeneous workpieces, a machining strategy adapted to the material properties. In practice, the process parameters used depend on the material that is machined. Due to the different material properties, the machinability is very different, therefore completely different tools and process conditions are chosen for an economical machining of the individual materials. While aluminum or low-alloy steels, for example, allow the use of high cutting speeds due to their low strength or high thermal conductivity, these would lead to severe tool wear when machining titanium or high-alloy steels. On the other hand, low cutting speeds, such as those used for titanium machining, can lead to increased adhesion and built-up edge formation when machining steel or aluminum. This results in both disadvantages in tool life and reduced component quality. Therefore, when combining different materials to form hybrid components, a compromise must be found with regard to process conditions in order to meet the component requirements economically. Chip formation has a decisive influence on the final component quality. In the present work therefore the chip formation mechanisms during orthogonal cutting of a steel-steel composite (SAE1020-SAE5140) are investigated for the first time. The composite is characterized by different material properties. However, in order to meet the required dimensions and tolerances of the final geometry, a compromise regarding the choice of process parameters has to be made. Up to now, there are no investigations concerning chip formation of hybrid components. The present study is intended to provide an understanding of the machinability of hybrid components in relation to process parameters and cutting edge microgeometry.

\section{Materials and experimental setup}

In the present work the machining behavior of hybrid components of SAE1020 and SAE5140 was examined by microcinematography. In addition to the high-speed recordings, process forces and process vibrations during the orthogonal cutting investigations were recorded and analyzed.

\subsection{Material properties and sample preparation}

In the presented work hybrid components with two different steel alloys, SAE1020 and SAE5140, were investigated. The chemical composition of the materials used are shown in Table 1 . The materials differ significantly in their carbon and chromium content.

At first the blanks were joined by a friction welding process. Friction welding (EN ISO 4063: process 42) is a welding process from the group of press-welding. In this process, two parts are moved relative to each other under pressure, with the components touching each other at the contact surfaces. The resulting friction causes the material to heat up and plasticise $[4,14]$. For the friction welding process, shafts with a diameter of $\mathrm{d}=40 \mathrm{~mm}$, a length of $\mathrm{l}=220 \mathrm{~mm}$ for SAE1020 and $1=150 \mathrm{~mm}$ for SAE5140, were used. The friction welding was carried out using a friction speed of $\mathrm{n}=2000 \mathrm{~min}^{-1}$, a friction pressure of $p=60 \mathrm{MPa}$ and an infeed of $\mathrm{s}=4 \mathrm{~mm}$. The final bond was then generated with a compression of $p=150 \mathrm{MPa}$ and a compression time of $t=6 \mathrm{~s}$ (Fig. 1b-1).

In the next step the friction weld bead was removed by longitudinal turning. The required contour for orthogonal cutting investigations was then produced by different milling processes. Subsequently, the hybrid components were heattreated to achieve the required hardness. They were hardened at a temperature of $860{ }^{\circ} \mathrm{C}$ for $45 \mathrm{~min}$, then quenched in a water bath and finally annealed at $150^{\circ} \mathrm{C}$ for $60 \mathrm{~min}$. In Fig. 1a the mechanical properties of the investigated materials after the heat treatment are summarized. The differences in hardness between the two materials are remarkable. SAE5140 with $612 \mathrm{HV} 1$ is almost twice as hard as SAE1020 with a hardness value of $258 \mathrm{HV} 1$. The microstructure images in Fig. 1a show the differences between both materials. SAE1020 is characterized by a ferritic-pearlitic microstructure while SAE5140 consists of a homogeneous martensitic microstructure. This is the reason for the difference in hardness of both materials. To compensate the hardening distortions caused by heat treatment, the planed samples were ground plane-parallel in the final step (not depicted in Fig. 1).

\subsection{Cutting edge preparation}

Cutting edge rounded indexable inserts of type SNMA 150612 were used for the orthogonal cutting investigations. For a precise preparation of the cutting edge and for the production of different cutting edge roundings, the movement of the insert

Table 1 Material composition

\begin{tabular}{llllllllll}
\hline Unit [\%] & $\mathrm{Fe}$ & $\mathrm{Mn}$ & $\mathrm{C}$ & $\mathrm{Si}$ & $\mathrm{Cu}$ & $\mathrm{Cr}$ & $\mathrm{Ni}$ & $\mathrm{Mo}$ & Other \\
\hline SAE1020 & 98.15 & 0.833 & 0.222 & 0.225 & 0.219 & 0.111 & 0.093 & 0.023 & 0.124 \\
SAE5140 & 97.2 & 0.742 & 0.420 & 0.211 & 0.151 & 1.04 & 0.082 & 0.039 & 0.115
\end{tabular}


(a)

material properties

\begin{tabular}{|c|c|c|c|}
\hline & & SAE1020 & SAE5140 \\
\hline density $\rho$ & $\mathrm{g} / \mathrm{cm}^{3}$ & 7.87 & 7.72 \\
\hline yield point $R e$ & $\mathrm{MPa}$ & 753.7 & 800 \\
\hline tensile strength $R m$ & $\mathrm{MPa}$ & 1034.7 & 1015.7 \\
\hline young's modulus $E$ & $\mathrm{GPa}$ & 200 & 210 \\
\hline hardness $H V$ & $\mathrm{HV} 1$ & 258 & 612 \\
\hline thermal conductivity $\lambda$ & $\mathrm{W} / \mathrm{m} \cdot \mathrm{K}$ & 51.9 & 42.6 \\
\hline
\end{tabular}

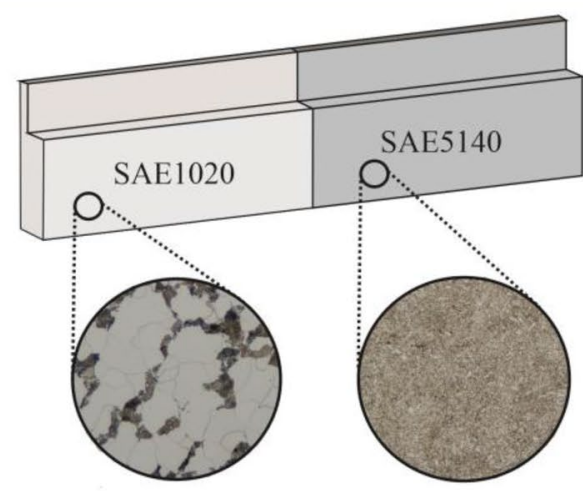

(b) (1) initial state: friction welded shaft
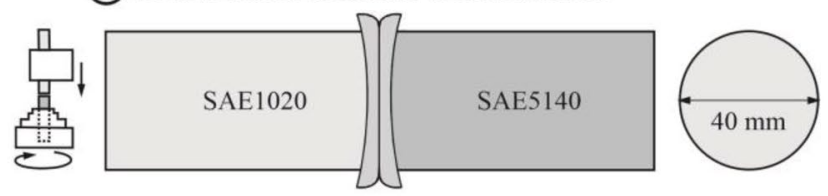

(2) removing welding bead, milling the contour
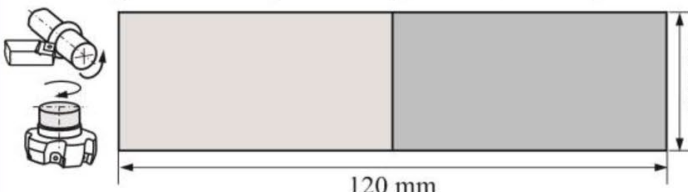

$120 \mathrm{~mm}$

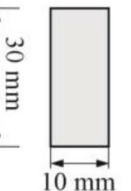

(3) milling of final geometry

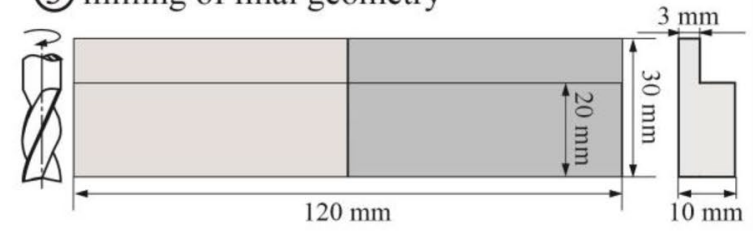

(4) heat treatment

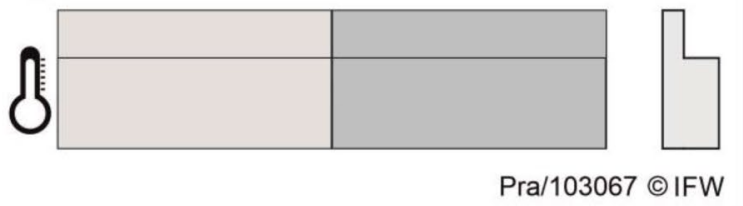

Fig. 1 Material properties after heat treatment (a) and preparation of hybrid samples for orthogonal cutting investigations (b)

during brushing was realized by a robot. An industrial robot of type KUKA KR16 is used for this purpose (Fig. 2, right).

With a load capacity of $16 \mathrm{~kg}$, six axes and a positioning accuracy of $< \pm 0.05 \mathrm{~mm}$, the robot has the necessary technical characteristics for precise cutting edge preparation. The indexable insert is mechanically clamped at the end of the robotic arm via a clamping device. In order to increase the accuracy, the positioning of the inserts is supported by additional measuring technology. An impact sound sensor is used to detect the contact of the indexable inserts with the brush. The applied tool is a brush containing $\mathrm{SiC}$ grains with a size of $240 \mu \mathrm{m}$. The bonding of the single fibres consists of a temperature-stable polymer. The setup for the preparation of the cutting edge is shown in Fig. 2 on the right. The process setting variables are brushing speed $\mathrm{v}_{\mathrm{c}}$, brushing time $t_{b}$, brushing depth $a_{z}$ and brush setting angle $\varphi_{z}$. By varying these process parameters, two symmetrical cutting edge roundings with $\mathrm{S}_{\alpha}=\mathrm{S}_{\gamma}=35 \mu \mathrm{m}$ and $\mathrm{S}_{\alpha}=\mathrm{S}_{\gamma}=75 \mu \mathrm{m}$ were prepared. The cutting edge roundings were produced in sufficient numbers so that one cutting edge could be used for one test. Thus an influence of tool wear on the orthogonal cutting results could be excluded. After the cutting edge preparation the inserts were double-coated with $\mathrm{Al}_{2} \mathrm{O}_{3}$ and TiCN using a CVD process at Walter AG. Size and deviation of the actual geometry of the cutting edge roundings after coating in comparison to the target geometry are shown in Fig. 2 on the left. With a tolerance of $\pm 5 \mu \mathrm{m}$ the produced geometries are within the intended range. In order to investigate the influence of different cutting edge roundings on chip formation mechanisms the coated SNMA 150612 WAK20 inserts were then used in the orthogonal cutting investigations.

\subsection{Machining}

The influence of cutting speed $\mathrm{v}_{\mathrm{c}}$, undeformed chip thickness $h$ and cutting edge microgeometry $S_{\alpha} / S_{\gamma}=\bar{S}$ on chip formation mechanisms in hybrid components is determined by means of microcinematography during orthogonal cutting. The orthogonal cutting process used here is a planing process (Fig. 3).

High-speed images of chip formation are taken during orthogonal cutting process. At the same time process forces and tool vibrations are measured simultaneously. The tool is rigidly clamped in a tool holder. The translatory movement of the hybrid samples is achieved by means of a jerk-decoupled linear direct drive moving the workpiece table. The workpiece table has a maximum stroke movement of $\mathrm{s}=1.000 \mathrm{~mm}$. The maximum cutting speed is $\mathrm{v}_{\mathrm{c}}=180 \mathrm{~m} / \mathrm{min}$ with a force of 

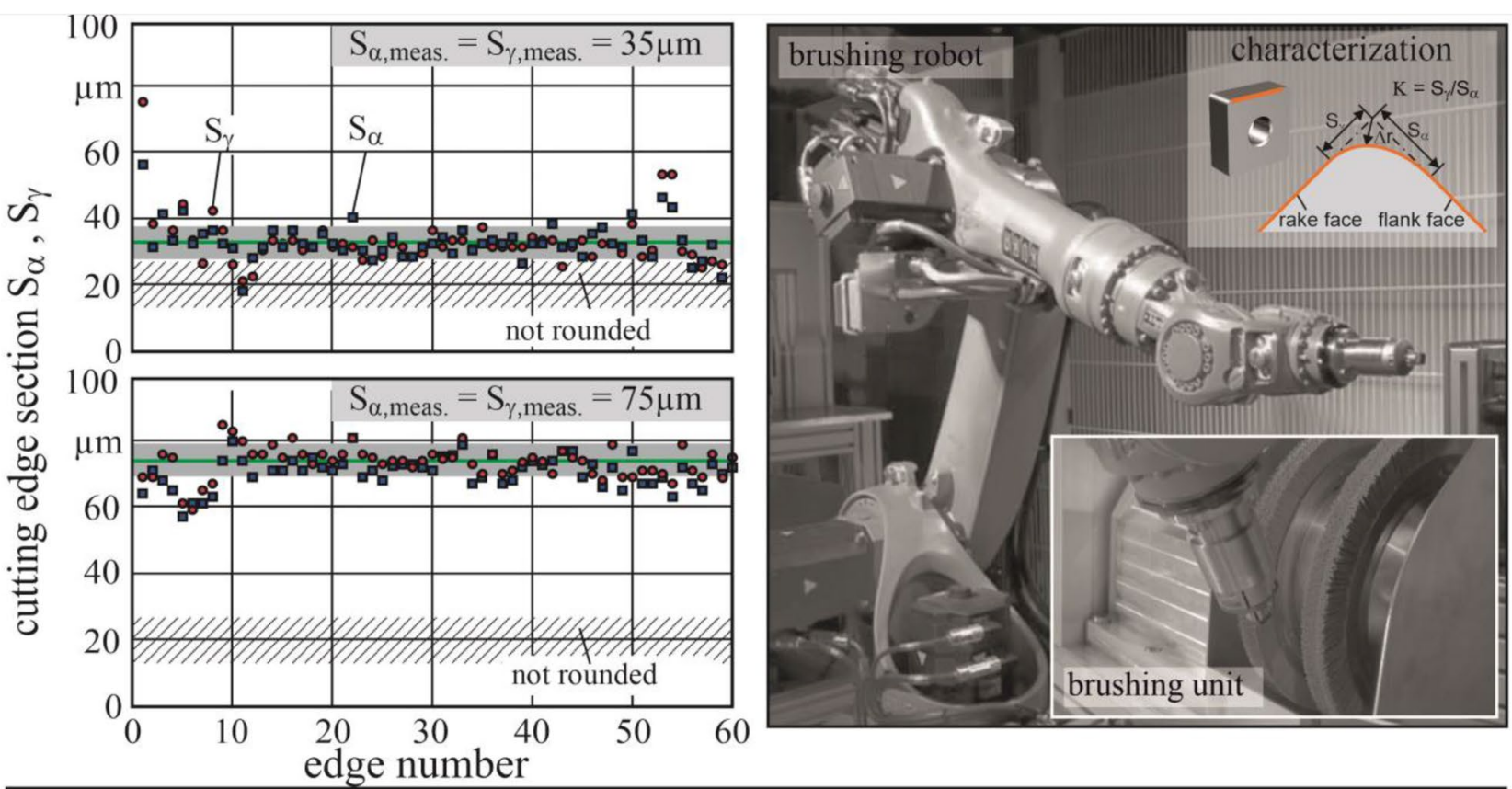

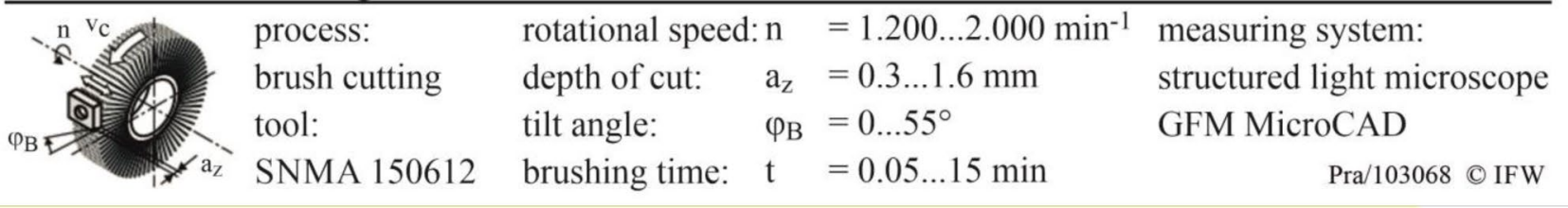

Fig. 2 Preparation of the cutting edge rounding with the bend-arm robot KUKA KR16

$\mathrm{F}=3.6 \mathrm{kN}$. A laser vibrometer from Polytec is used to record tool vibrations during the orthogonal cutting process. The system consists of a measuring head (type OFV-303) and a controller (OFV-3001). Axial vibrations of the tool during the orthogonal cutting process are recorded. The laser vibrometer uses the laser-Doppler-technique. This technique is characterized by the double shift of a coherent light beam that hits a vibrating surface and is reflected. The occurring interferences are digitized as path information by means of an $\mathrm{A} / \mathrm{D}$ converter card of type BNC 2090 from National Instruments. The signals are processed, visualized and stored in the LabVIEW programming environment using software developed at the Institute of Production Engineering and Machine Tools. The sampling rate of the software used is $50 \mathrm{kHz}$. This allows even small vibrations to be reconstructed exactly. The vibrometer thus enables a non-contact measurement of the vibrations of an object based on laser interferometry. The workpiece is mechanically clamped on the table. This enables the absorption of process forces up to $F_{\max }=10 \mathrm{kN}$. A sapphire glass plate is clamped between the sample and the lens of the high-speed camera to ensure a steady state of deformation. Here it is assumed that the simplification to a plane deformation state in the orthogonal section (two-dimensional case) is allowed due to the significantly larger cutting width $\mathrm{b}$ compared to the chip thickness $\mathrm{h}$. In this case, an infinitely thin shear plane is assumed, in which the sliding of the material takes place in individual "segments" which have a homogeneous deformation state. The shear plane runs from the cutting edge to the surface of the workpiece in which the deformation takes place. At the same time, the sapphire glass plate prevents lateral material flow. To avoid material flow and contact of the tool with the sapphire glass, the corner radii of the tool insert are ground off. In addition, immersion oil is used to reduce friction between sapphire glass and tool. In the investigation on orthogonal cutting, the undeformed chip thickness $h$ is varied in three steps, the cutting speed $\mathrm{v}_{\mathrm{c}}$ in three steps and the cutting edge microgeometry $\bar{S}$ in two steps. The workpiece length is $\mathrm{L}=120 \mathrm{~mm}$. The workpiece is chamfered at the front so that the cutting edge does not break when the tool enters the workpiece. The cutting width is set to $b=3 \mathrm{~mm}$. The maximum workpiece height is $\mathrm{H}=32 \mathrm{~mm}$. The examined process parameters during the orthogonal cutting operation are summarized in Table 2.

\section{Results and discussion}

In this chapter the results of the orthogonal cutting investigations with varying process parameters and cutting edge microgeometries are presented. In this respect, the chip formation mechanisms were evaluated using the high-speed 


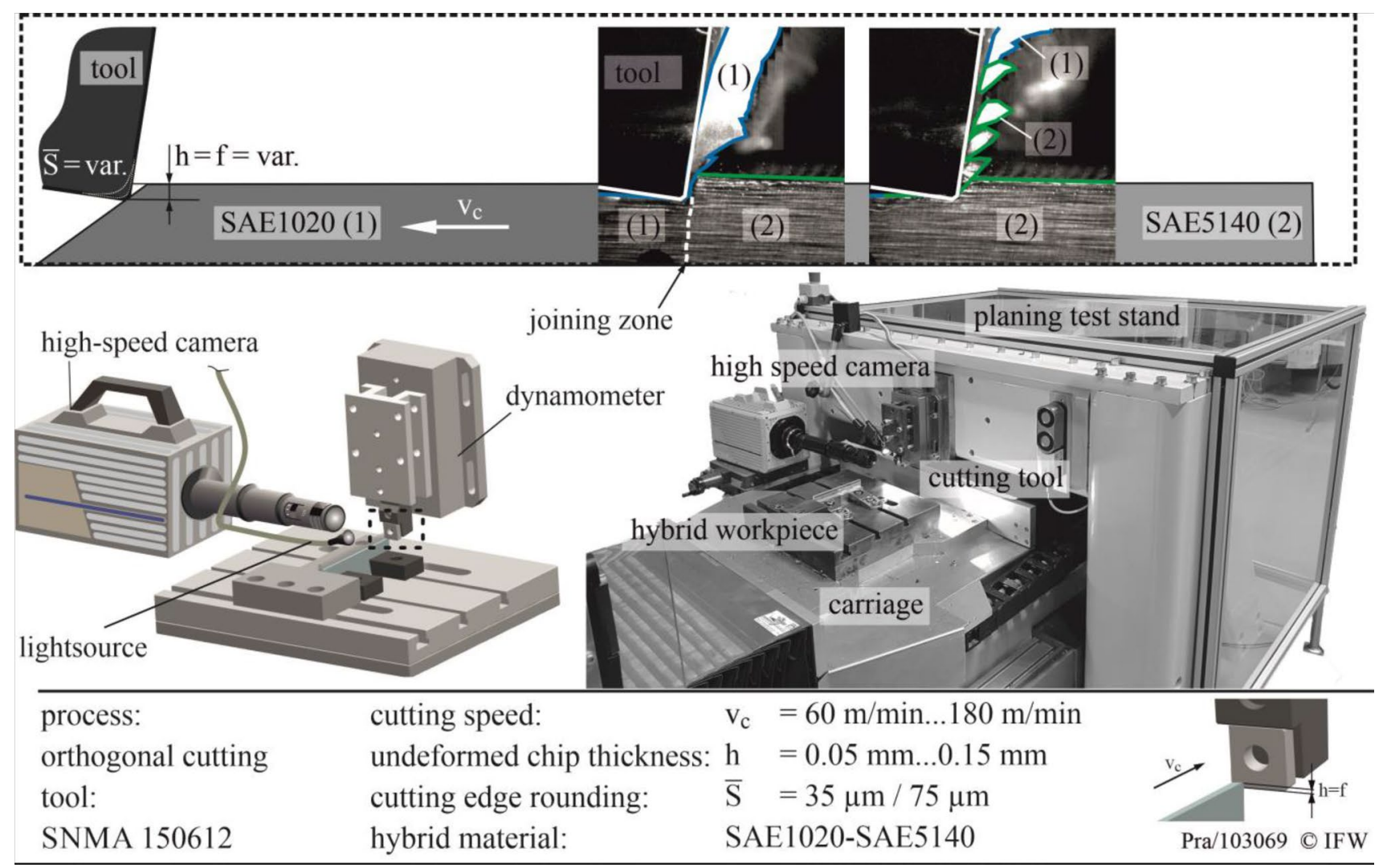

Fig. 3 Experimental setup at the orthogonal cutting test bench

Table 2 Process parameters of the orthogonal cutting investigation

\begin{tabular}{lll}
\hline & Unit & SAE1020-SAE5140 \\
\hline Cutting speed $\mathrm{v}_{\mathrm{c}}$ & $\mathrm{m} / \mathrm{min}$ & $60 ; 120 ; 180$ \\
Undeformed chip thickness $\mathrm{h}$ & $\mathrm{mm}$ & $0.05 ; 0.1 ; 0.15$ \\
Cutting depth $\mathrm{a}_{\mathrm{p}}$ & $\mathrm{mm}$ & 0.3 \\
Cutting edge geometry $\overline{\mathrm{S}}$ & $\mu \mathrm{m}$ & $35 ; 75$ \\
Cutting direction & - & Soft (SAE1020)- \\
& & hard (SAE5140) \\
\hline
\end{tabular}

images. Correlations with the measured process forces and resulting surface properties were analyzed. For better clarity, only the feed forces are shown because the feed forces correspond to the normal forces during orthogonal cutting and therefore reach the maximum values in this investigation.

\subsection{In-situ machining analysis}

In Fig. 4 the influence of undeformed chip thickness $h$ on chip formation is presented. The chip formation depends on the material properties as well as on the undeformed chip thickness. In Fig. 4 the experimental microcinematographic and vibrometer results for SAE1020-SAE5140 hybrid components under variation of the undeformed chip thickness $\mathrm{h}$ from 0.05 to $0.15 \mathrm{~mm}$ are displayed.

The cutting speed $\mathrm{v}_{\mathrm{c}}$ was held constant at $120 \mathrm{~m} / \mathrm{min}$. It can be seen that continuous chip formation in SAE1020 changes abruptly in segemented chip formation in SAE5140. The reason for this is the significantly higher hardness due to the martensitic microstructure of SAE5140 which leads to a segmented chip formation. When the material hits the cutting edge of the tool, it is compressed until, at a high degree of deformation, the fracture stress of the workpiece material is exceeded and the material tears at the cutting edge under the effect of normal stress. The following material causes the crack formation, until finally the surface is reached and the chip element is separated from the workpiece. According to the state of the art, the chip segmenting crack runs intercrystalline. It is therefore irregular, shape and size of the separated chip elements are random. During shear chip formation the chip thickness $h^{\prime}$ varies over the chip. The chip thickness $h^{\prime}$ is therefore given as an average value between maximum and minimum chip thickness $\mathrm{h}^{\prime}$. This must be taken into consideration for the evaluation. In SAE1020, on the other hand, the lower hardness and significantly lower thermal conduction coefficient leads to thermomechanical stress in the cutting zone and causes continuous chip formation. A change in chip formation from a continuous 


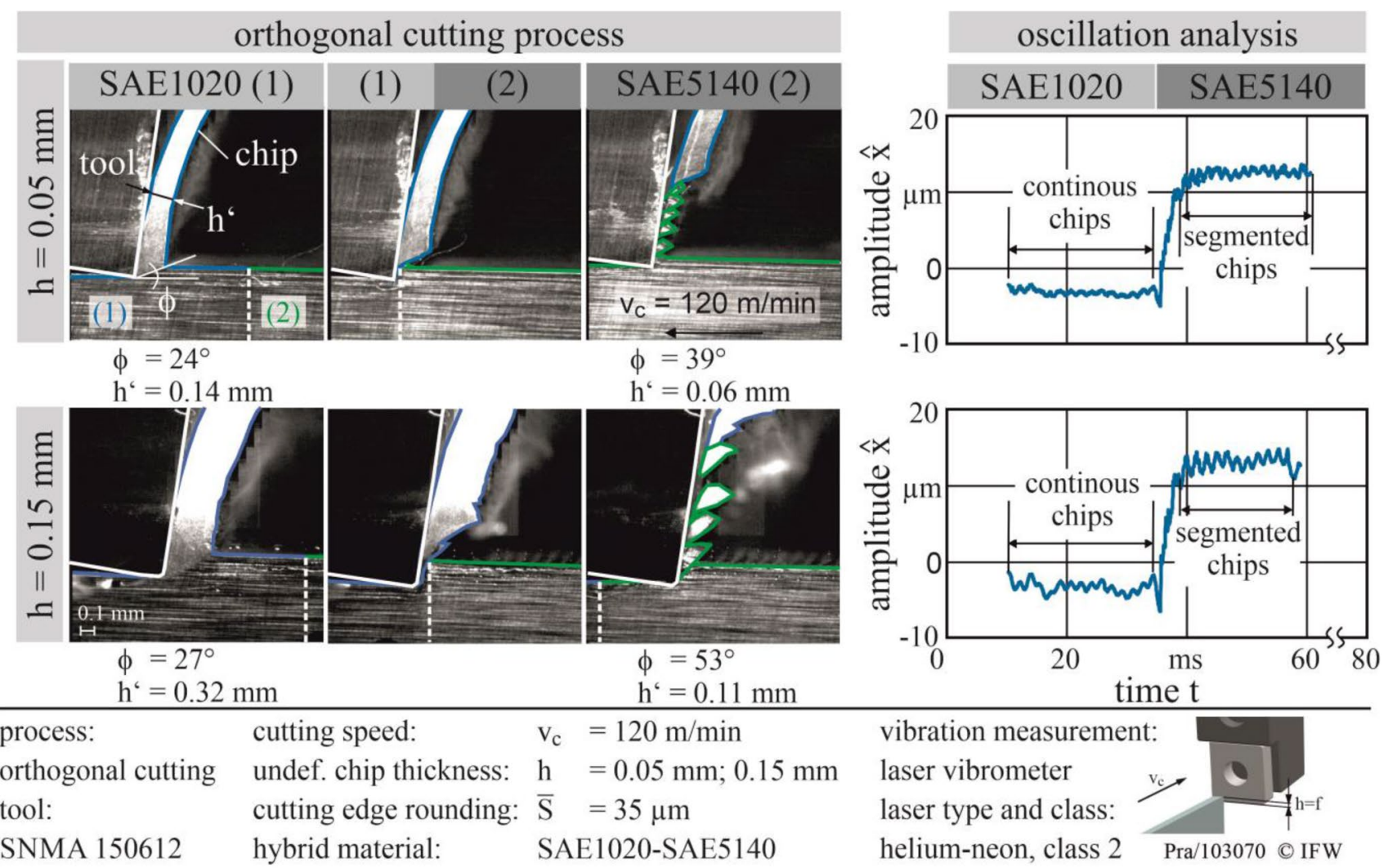

Fig. 4 Influence of undeformed chip thickness on chip formation (left) and in-situ oscillation analysis (right) during orthogonal cutting of hybrid components SAE1020-SAE5140

to a segmented chip, is also followed by a change in chip thickness $\mathrm{h}^{\prime}$ and shear angle $\phi$. The shear angle increases during segmented chip formation while the chip thickness decreases. Consequently, the shear angle $\phi$ significantly influences chip formation. Large shear angles lead to segmented chip formation. If the undeformed chip thickness $h$ is increased, the continous chip formation in SAE1020 is maintained, but the shear localization changes in SAE5140. A higher chip thickness therefore leads to a higher shear localization caused by an increased shear angle. While the chip compression $\lambda_{h}=h^{\prime} / h$ in SAE1020 remains almost constant as the chip thickness increases, the chip compression in SAE5140 decreases significantly. The chip compression represents the deformability of the material. As the chip compression $\lambda_{h}$ decreases, the deformability of the material also decreases. Deformation reduction is accompanied by an increase in the shear angle, i.e. the cross-sectional area of the undeformed chip decreases. This also causes a decrease of the cutting force. In Fig. 4 (right) the results of the vibration tests are shown. As with chip formation, the vibration amplitude increases during segmented chip formation. The higher tool vibration in SAE5140 leads to higher roughness of the created surface and consequently to a reduction of surface quality. Furthermore, the higher vibration amplitude in SAE5140 leads to higher process force oscillations which directly influence the mechanical load of the tool insert used.

In Fig. 5 the results of chip formation mechanisms in dependence of the cutting speed are represented. Microkinematic images at two different cutting speeds $\mathrm{v}_{\mathrm{c}}=60 \mathrm{~m} /$ min and $\mathrm{v}_{\mathrm{c}}=180 \mathrm{~m} / \mathrm{min}$ are shown. It is noticeable that with increasing cutting speed the shear angle increases. As the cutting speed increases, a local temperature increase occurs in front of the cutting edge. This leads to a softening of the material, which increases the formation ability of the material. However, the chip forms of SAE1020 (continous chips) and SAE5140 (segmented chips) remain unchanged. The influence of different cutting speeds $\left(\mathrm{v}_{\mathrm{c}}=60,120\right.$, $180 \mathrm{~m} / \mathrm{min})$ and undeformed chip thicknesses $(\mathrm{h}=0.05,0.1$, $0.15 \mathrm{~mm}$ ) on tool vibrations is shown on the right in Fig. 5 . The vibration amplitudes are always higher in SAE5140 than in SAE1020 due to segmented chip formation. The vibration amplitude decreases with increasing cutting speed. The reason for this is the softening of the material due to the higher process temperature. For this reason the yield point of the material decreases. A change in undeformed chip thickness leads to different effects depending on the material being machined. In SAE1020, an increase in undeformed chip thickness $\mathrm{h}$ leads to an increase in the vibration amplitude. 


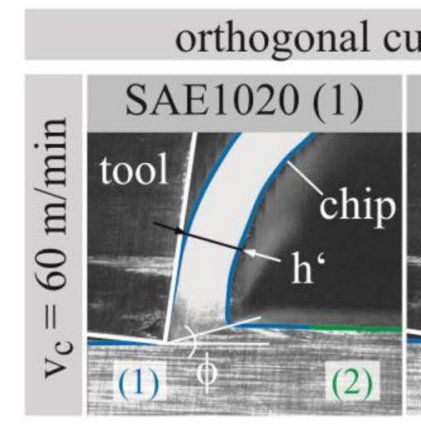

$\phi=19^{\circ}$

$\mathrm{h}^{\mathrm{c}}=0.29 \mathrm{~mm}$

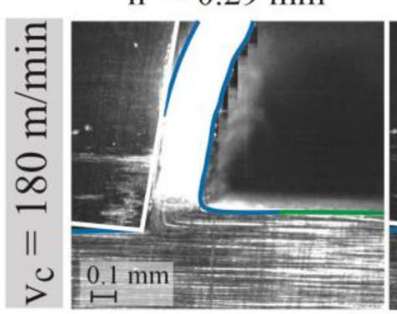

$\phi=28^{\circ}$

$\mathrm{h}^{\mathrm{c}}=0.24 \mathrm{~mm}$

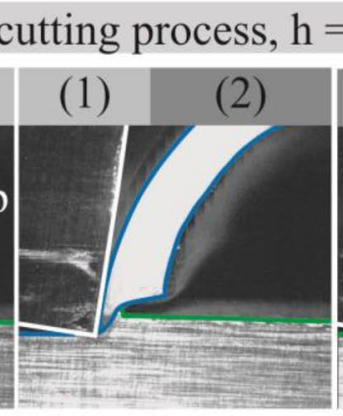

(1)
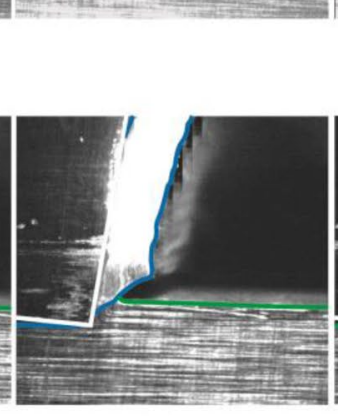

$$
\text { (n) }
$$

cutting speed:

process:

orthogonal cutting

tool:

undef. chip thickness:

SNMA 150612 hybrid material:

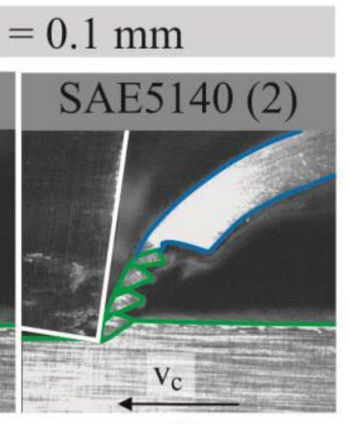

$\phi=35^{\circ}$

$\mathrm{h}^{\mathrm{c}}=0.09 \mathrm{~mm}$

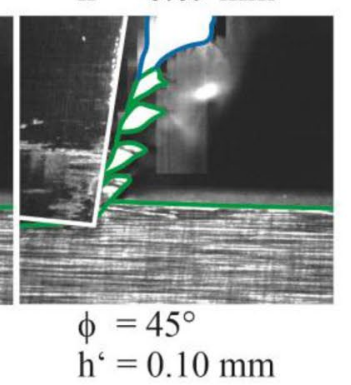

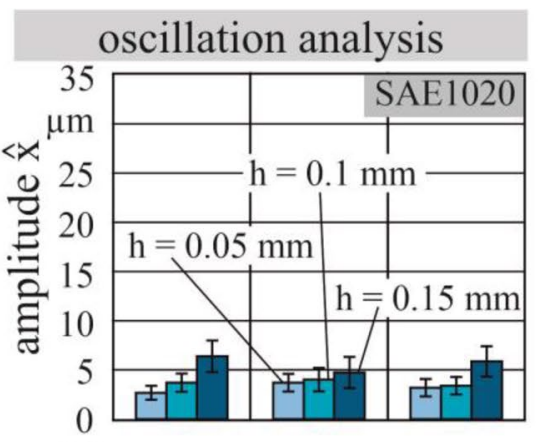

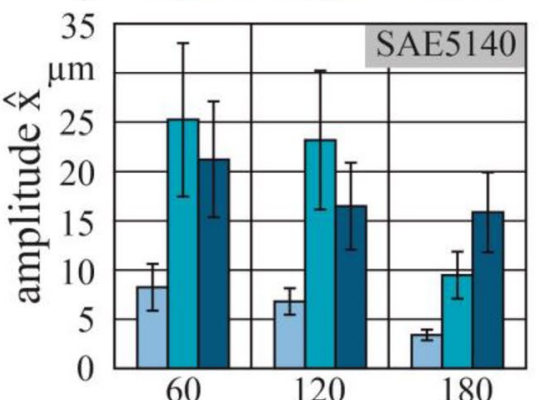

cutting speed $\mathrm{v}_{\mathrm{c}}[\mathrm{m} / \mathrm{min}]$

Fig. 5 Influence of cutting speed on chip formation (left) and oscillation analysis of the tool depending on process parameters during orthogonal cutting of hybrid material SAE1020-SAE5140

The reason for this is the increasing mechanical stress with increasing undeformed chip thickness. In SAE5140, the vibration amplitude also increases with increasing undeformed chip thickness. However, an interaction with the cutting speed takes place here. As already mentioned, irregular chip formation could be the reason for this, which is why a clear correlation cannot be identified.

The influence of cutting speed $\mathrm{v}_{\mathrm{c}}$ and undeformed chip thickness h using a cutting edge rounding of $\bar{S}=75 \mu \mathrm{m}$ on the orthogonal cutting results is shown in Fig. 6. In analogy to a cutting edge rounding of $35 \mu \mathrm{m}$, the same chip formation mechanisms occur. Depending on the examined parameter range in SAE1020 continous chip formation and in SAE5140 segmented chip formation takes place. However, the chip compression $\lambda_{\mathrm{h}}$ in both material sections decreases with increasing undeformed chip thickness h. Consequently, the deformability decreases. The reduction in deformation is accompanied by an increase in shear angle, resulting in a decrease of the shear cross section. This also causes a decrease in the cutting force. Regarding the effect of cutting speed on chip formation, it can be seen that with a cutting edge rounding of $75 \mu \mathrm{m}$ the chip thickness remains constant with increasing cutting speed. However, compared to cutting edge rounding with $35 \mu \mathrm{m}$, in which the shear angle increases in both material areas, it only increases in the area of SAE5140 with a cutting edge rounding of $75 \mu \mathrm{m}$. The reason for this is that with increasing cutting speed the process temperature rises and thus causes the material to soften. This softening effect is enhanced due to the additional temperature increase caused by higher frictional effects during machining of the harder material SAE5140. Consequently the significantly higher process temperature in the harder material area leads to a softening of the material and thus promotes material flow.

\subsection{Process forces}

In Fig. 7 feed forces $F_{\underline{f}}$ for the examined cutting edge roundings $\overline{\mathrm{S}}=35 \mu \mathrm{m}$ and $\overline{\mathrm{S}}=75 \mu \mathrm{m}$ depending on the process parameters undeformed chip thickness $h$ and cutting speed $v_{c}$ are shown. Due to the higher material hardness in SAE5140 than in SAE1020 the feed force is always higher in SAE5140 and consequently leads to a higher tool displacement in this material range. The continuous chip formation in SAE1020 and the segmented chip formation in SAE5140 are recognizable in the force profiles. While the fluctuations in feed 


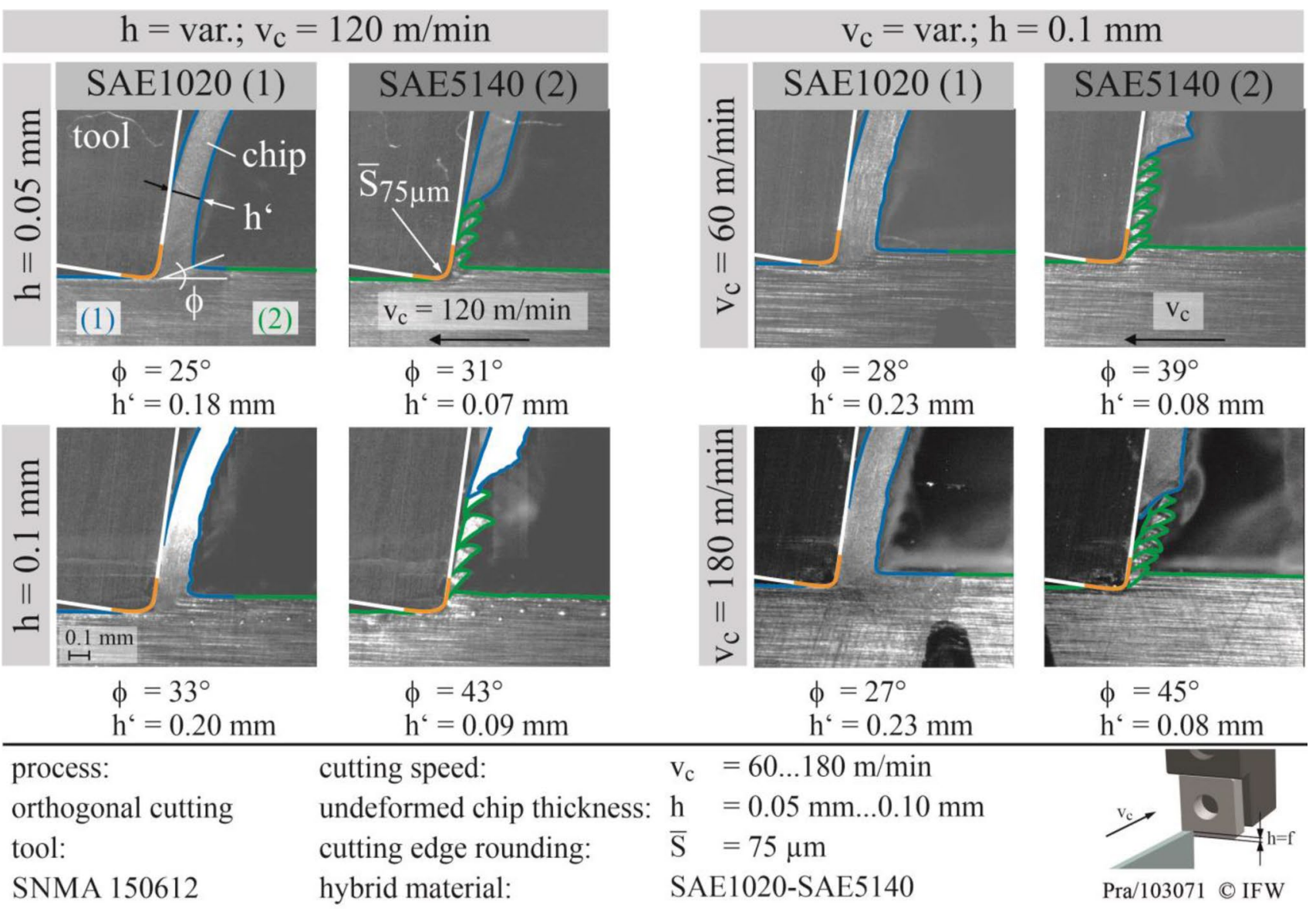

Fig. 6 Influence of process parameters on chip formation using a cutting edge rounding of $\bar{S}=75 \mu \mathrm{m}$ during orthogonal cutting of hybrid material SAE1020-SAE5140

force during continuous chip formation are very low, the significantly higher oscillation of the feed forces during segmented chip formation is obvious. These oscillations are significantly higher at low cutting speeds. The reason for this is that at low cutting speeds the deformability of the material is lower and thus the resistance of the material to plastic deformation is higher. This effect is reduced with increasing cutting speed due to higher process temperatures.

In addition, a further dynamic cutting force component is generated as a result of friction between chip and rake face of the tool and between generated machined surface and tool flank face. However, this contribution is small, especially by using carbide tools at high cutting speeds. In the formation of segmented chips, the cutting force profiles thus represent a stochastic signal whose functional relationship cannot be specified analytically.

An interesting aspect is the force shift in the material transition area due to different material properties. By comparison of the influence of the undeformed chip thickness $h$ on the measured feed forces in relation to the cutting edge rounding, different effects can be seen. When using a cutting edge rounding of $\overline{\mathrm{S}}=35 \mu \mathrm{m}$, the force shift in the transition area increases with increasing undeformed chip thickness. A possible reason for this could be the increase in tool deflection with increasing undeformed chip thickness. This is because the chip cross section increases with increasing undeformed chip thickness and consequently the specific cutting force increases according to Kienzle. In SAE5140, the tool deflection is higher due to the higher hardness of the material and leads to a greater force difference at a higher undeformed chip thickness. With a larger cutting edge rounding, the force step in the material transition zone remains almost the same. The process forces increase proportionally with the undeformed chip thickness. The force difference at an undeformed chip thickness of $h=0.15 \mathrm{~mm}$ is significantly lower compared to the smaller rounding. The tool displacement decreases with a larger cutting edge rounding in the transition zone of the hybrid component and therefore leads to a smaller force difference. This is a possible reason for the smaller force difference. It was also found that the chip compression decreases when using a larger cutting edge rounding, resulting in a decrease of the chip 

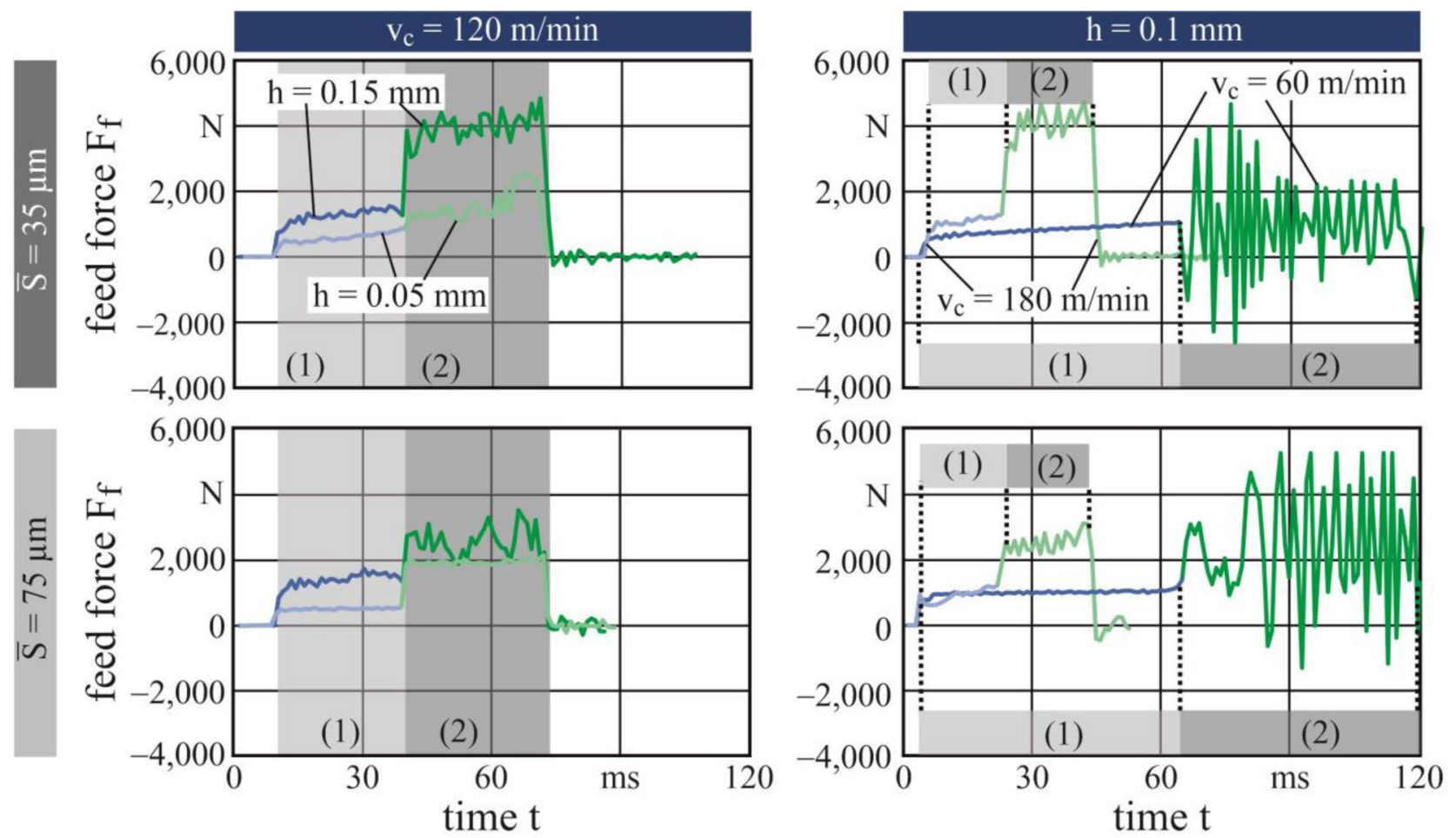

process:
orthogonal cutting
tool:

SNMA 150612

\section{cutting speed:} undeformed chip thickness: cutting edge rounding: hybrid material: $\mathrm{v}_{\mathrm{c}}=60 \ldots 180 \mathrm{~m} / \mathrm{min}$

$\mathrm{h}=0.05 \mathrm{~mm} \ldots 0.15 \mathrm{~mm}$

$\overline{\mathrm{S}}=35 \mu \mathrm{m} ; 75 \mu \mathrm{m}$

SAE1020 (1) - SAE5140 (2)

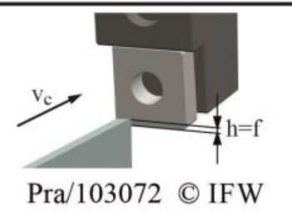

Fig. 7 Influence of cutting edge geometry on feed forces during orthogonal cutting of SAE5120-SAE1020 welded shaft

cross section and thus a reduction of the forces. This effect can also be observed under variation of the cutting speed. In addition, the different thermal conduction coefficients of the materials cause a different thermal conduction of the generated process temperature in the material. A larger cutting edge rounding leads to higher process temperatures due to the larger contact surface between tool and workpiece. The frictional power increases. Consequently, the heat in the shear cross section increases. This results in a reduction of the force difference in the material transition area. The effect of the heat input significantly increases with increasing cutting speed.

\subsection{Surface roughness measurement}

Finally, optical surface examinations of the planed hybrid samples were carried out to investigate the effect of the different chip formation mechanisms on the surface properties (Fig. 8).

Here too, the influence of different chip formation mechanisms on the resulting surface can be seen. For all samples, the surface roughness in SAE1020 is significantly lower than in SAE5140. The continuous chip formation results in a smoother surface with a lower roughness compared to the segmented chip formation. The vibrations that the tool experiences due to chip segmentation are also transmitted to the surface and explain the fluctuations in process forces which are depicted in Fig. 7.

In terms of surface quality, cutting speed has a significantly higher influence than undeformed chip thickness. The influence of undeformed chip thickness on the generated machined surface is shown as an example for a cutting edge rounding of $\bar{S}=35 \mu \mathrm{m}$ (Fig. 8). With increasing undeformed chip thickness, the surface roughness as well as the difference in the height profile $\Delta \mathrm{H}$ in the material transition area increase. The reason for this is the decreasing deformability of the machined material with increasing undeformed chip thickness, which leads to a worsening of the new created surface. The influence of the cutting speed is evident (Fig. 8, right). As the cutting speed increases, the surface roughness in SAE1020 is significantly reduced from $\mathrm{Rz}=4.19$ to $0.63 \mu \mathrm{m}$, as the material flows better at higher temperatures, leaving a smooth surface. Due to the extreme variations in both chip segmentation and feed forces, the 


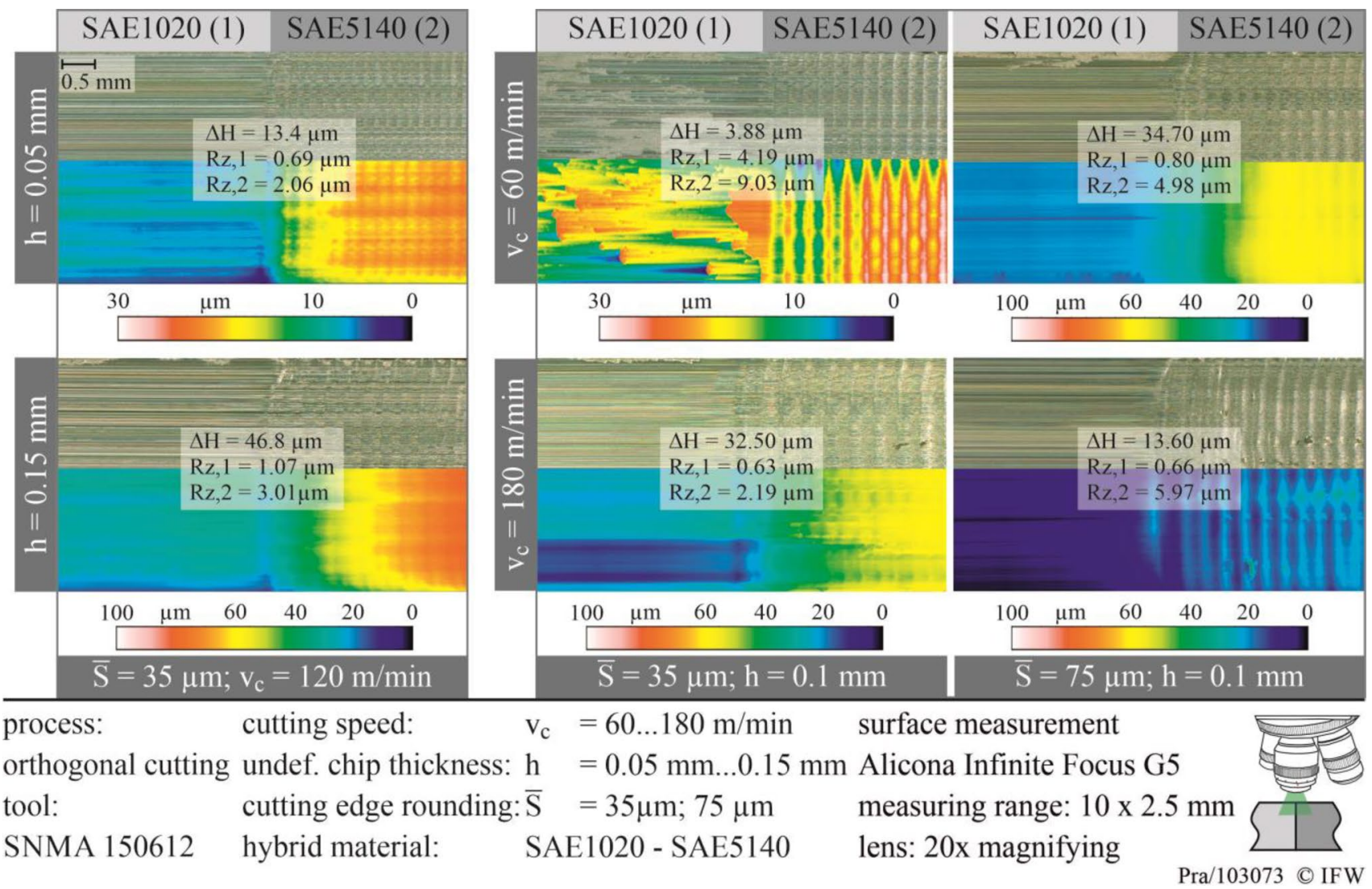

Fig. 8 Influence of process parameters and cutting edge geometry on surface roughness and topography of SAE1020-SAE5140 hybrid samples

single influences on surface roughness of SAE5140 cannot be clearly explained. While an improvement of the surface roughness in SAE5140 can be seen with a cutting edge rounding of $\bar{S}=35 \mu \mathrm{m}$, the use of a larger cutting edge roundingleads to an increase in surface roughness. However, similar to the process forces, the difference in the height profile in the material transition zone is significantly smaller when using a large cutting edge rounding.

\section{Summary and outlook}

In this paper the machining behavior of hybrid SAE1020-SAE5140 components is analyzed by using an orthogonal cutting process. The chip formation depends on the microstructure of the material and on orthogonal cutting parameters. Therefore the cutting edge rounding $\overline{\mathrm{S}}$ $(35 \mu \mathrm{m}, 75 \mu \mathrm{m})$, the cutting speed $\mathrm{v}_{\mathrm{c}}(60,120,180 \mathrm{~m} / \mathrm{min})$ and the undeformed chip thickness $\mathrm{h}(0.05,0.1,0.15 \mathrm{~mm})$ were varied. The material removal mechanisms were investigated, indicating the significant influence of different material properties and process parameters on the machinability of the investigated hybrid SAE1020-SAE5140 component. The hybrid component is characterized by the fact that the materials differ significantly in their hardness values and microstructure. This difference is also noticeable in the chip forms. The properties of SAE1020 lead to the formation of continuous chips, while in SAE5140 segmented chips are formed. In the parameter space under investigation, the chip forms remain unchanged in the respective material areas. The variation of process parameters significantly influences the shear angle $\phi$, the chip thickness $\mathrm{h}^{\prime}$ and the chip compression $\lambda_{\mathrm{h}}$. In the material transition zone there is an abrupt change from continuous to segmented chip formation. The abrupt change is also clearly visible in the profile of the process forces as well as in the height profile of the generated machined surface. The cutting speed $\mathrm{v}_{\mathrm{c}}$ has a significant influence on the shape of the formed chips and the newly generated machined surface of hybrid components. An increase in cutting speed leads to an improvement in surface roughness in the corresponding material areas. The reason for this is that an increase in the cutting speed leads to a temperature rise. This results in a softening of the material and thus improves the flow of the material. An increase in undeformed chip thickness $h$ causes an increase in chip thickness $\mathrm{h}^{\prime}$ during continuous chip formation. The large fluctuations of chip thickness during segmented chip formation make it difficult to identify concrete relationships between process 
parameters, cutting edge rounding and chip formation. If the process forces are considered, they increase with increasing undeformed chip thickness. However, a greater rounding of the cutting edge leads to a reduction of the force shift in the transition zone. This suggests that a higher cutting edge rounding leads to a lower gradient of the resulting subsurface properties in the material transition zone. However, this effect seems to greatly depend on the undeformed chip thickness. In further investigations, the transferability of the observed effects to external longitudinal turning tests will be checked and the influence of process parameters on resulting subsurface properties will be additionally analyzed.

Acknowledgements The results presented in this paper were obtained from the Collaborative Research Centre 1153 "Process chain to produce hybrid high performance components with Tailored Forming" funded by the Deutsche Forschungsgemeinschaft (DFG, German Research Foundation) within the subproject B4-252662854. The authors thank the DFG for the financial support of this project.

Funding Open Access funding enabled and organized by Projekt DEAL.

Open Access This article is licensed under a Creative Commons Attribution 4.0 International License, which permits use, sharing, adaptation, distribution and reproduction in any medium or format, as long as you give appropriate credit to the original author(s) and the source, provide a link to the Creative Commons licence, and indicate if changes were made. The images or other third party material in this article are included in the article's Creative Commons licence, unless indicated otherwise in a credit line to the material. If material is not included in the article's Creative Commons licence and your intended use is not permitted by statutory regulation or exceeds the permitted use, you will need to obtain permission directly from the copyright holder. To view a copy of this licence, visit http://creativecommons.org/licenses/by/4.0/.

\section{References}

1. Giampieri A, Ling-Chin J, Ma Z, Smallbone A, Roskilly AP (2020) A review of the current automotive manufacturing practice from an energy perspective. Appl Energy 261:1-29. https://doi. org/10.1016/j.apenergy.2019.114074

2. Huang J, Chang Q, Arinez J, Xiao G (2019) A maintenance and energy saving joint control scheme for sustainable manufacturing systems. Proced CIRP 80:263-268. https://doi.org/10.1016/j.proci r.2019.01.073
3. Schmidt M, Bauer J, Haubach C (2017) Ressourceneffiziente Herstellung mechanischer Verbindungselemente. In 100 Be-triebe für Ressourceneffizienz, Band 1. Springer Spektrum, Berlin, pp 461-480

4. Sköck-Hartmann B, Gries T (2011) Non-crimp fabric composites-manufacturing, properties and applications. Woodhead Publishing, Cambridge, pp 461-480

5. Cole GS, Sherman AM (1995) Leight weight materials for automotive applications. Mater Charact 35(1):3-9. https://doi. org/10.1016/1044-5803(95)00063-1

6. Behrens B-A, Bouguecha A, Frischkorn C, Huskic A, Stakhieva A, Duran D (2016) Tailored forming technology for three dimensional components: approaches to heating and forming. In: 5 th Conference on thermo mechanical processing, Milan, Italy, October 26-28th

7. Behrens B-A, Goldstein R, Guisbert D, Duran D (2018) Thermomechanical processing of friction welded steel-luminum billets to improve joining zone properties. In: 4th International conference on heat treatment and surface engineering in automotive applications (thermal processing in motion), Spartanburg, North Carolina, USA, 5th-7th June

8. Mildebrath M, Blohm T, Hassel T, Stonis M, Langner J, Maier HJ, Behrens B-A (2017) Influence of cross wedge rolling on the coating quality of plasma-transferred arc deposition welded hybrid steel parts. Int J Emerg Technol Adv Eng 7(7):2250-2459

9. Chugreeva A, Mildebrath M, Diefenbach J, Barroi A, Lammers M, Hermsdorf J, Hassel T, Overmeyer L, Behrens B-A (2018) Manufacturing of high performance bi-metal bevel gears through the combination of deposition welding and forging. Metals 8(11):898. https://doi.org/10.3390/met8110898

10. Breidenstein B (2011) Oberflächen und Randzonen hoch belasteter Bauteile. Leibniz Universität Hannover, Habilitationsschrift

11. Pawade RS, Joshi SS, Brahmankar PK (2008) Effect of machining parameters and cutting edge geometry on surface integrity of high-speed turned Inconel 718. Int J Mach Tools Manuf 48:15-28. https://doi.org/10.1016/j.ijmachtools.2007.08.004

12. Sadat AB, Bailey JA (1987) Residual stresses in turned AISI 4340 steel. Exp Mech 27(1):80-85. https://doi.org/10.1007/BF023 18868

13. Thiele JD (1998) An investigation of surface generation mechanism for finish hard turning of AISI 52100 steel. M.S. thesis, The George W. Woodruff School of mechanical engineering, Georgia Institute of Technlogy, Atlanta, GA

14. Witt G (2006) Taschenbuch der Fertigungstechnik. Carl Hanser Verlag, München (3-446-22540-4)

Publisher's Note Springer Nature remains neutral with regard to jurisdictional claims in published maps and institutional affiliations. 